\title{
Tourism Cross-cultural Propagation and the Corresponding Requirements for Foreign Language-speaking Tour Guides
}

\author{
Yongqiu Xie \\ College of Business Administration, Capital University of Economics and Business \\ Beijing 100026, China \\ Tel: 86-10-8272-3913 E-mail: xieyongqiu321@163.com
}

\begin{abstract}
Overseas tourist usually comes from different cultural backgrounds. On arrival of the traveling destination in China, they find themselves already in an entirely new environment. Besides sightseeing, leisure relaxation, shopping, entertainment and other enjoyments, they receive, more or less, edification from traditional Chinese culture. Actually, China's tour guide is spreading his native culture to the foreign guests. In this sense, guiding service for visitors from abroad is greatly different form that for domestic travelers, which poses a number of specific requirements for tour guides. To have a definite clarification of the requirements,, this dissertation makes some exploration on the special professional qualities that a foreign language-speaking tour guide should possess.
\end{abstract}

Keywords: Cross-cultural propagation, Foreign guest service, Special requirements

With special properties and requirements, foreign cultural propagation is different from that within a single ethnic cultural model. Such cultural differences require the relevant practitioners and scholars apply the opinions of cross-cultural psychology to the researches on the cultural commonality and difference between China and other nationalities so as to detect the compatibility of two different cultures. This is essential to the global propagation of the splendid Chinese culture. As an overseas guest-serving career, tour guiding performs the function of foreign propagation. Therefore, China's tour guides should develop special qualities for cross-cultural communication and become competent enough for the communication. Tourism cross-cultural communication concerns many aspects of the industry and this dissertation cannot present perspectives in every detail. So the present author only explores primarily on the following three issues:

\section{Characteristics and nature of tourism cross-cultural propagation}

\subsection{Nature}

Chinese culture goes back to ancient times. But, for quite a long period, only a small part of this treasury is opened to the world. To help the culture become understandable and appealing to the peoples of most countries, thus brilliant inheritance should be carried on with creativity and enthusiasm. As a channel of cultural propagation, tourism activity actualizes the movement of tourists through the economic operation of the industry.

This movement bears two properties. First, it does not constrain from the social system and cultural level of the travelers. Second, it is conducted across different regions and countries. This extensive trans-area movement contributes greatly to the frequent contacts and communications between different societies, economies and cultures, for on one hand, the visitor's cultural model is observed and adopted by the people of the destination regions and countries, and on the other hand, the visitors also directly observe the destination's historical sites of cultural interests, traditional customs and conventions and present cultural life of the native people. From the explanation and commentary by the tour guides, the visitors acquire their personal experience and perception and, furthermore, adopt the cultural merits of the destination people. In nature, such an in-the-tour humanity movement and the mutual influences on the peoples from different cultural backgrounds is a phenomenon of culture propagation and communication.

Foreign cultural propagation is different from that between different areas within the same cultural model. Under the latter circumstance, successively inherited cultural traditions of the same ethnic group make factors of cultural assimilation produce effect more powerfully than those of cultural conflicts although the cultural propagation within an ethnic group triggers conflicts also. But the foreign cultural propagation works in a quite different way. Different life styles and norms of behavior, and different cultural values and psychological patterns produce more non-affinitive factors than affinitive factors. Therefore, it is necessary to shorten the cultural mental disparity which derives from the special properties of two different cultures. As an achievement, the two cultures become understandable and respectable 
to each other and learn from each other to make up deficiencies respectively. China's tourism industry attracts great numbers of foreign travelers to the country, which offers convenience for the visitors to learn about and take close looks at China and the Chinese culture in a more direct and imaginative way. Consciously or not, China's tour guides are spreading their country's national culture to the outside world.

Attracting foreign visitors to promote the excellent culture of one's own nation is not a unique creation of China. It is a commonly adopted strategy by a large number of countries. In Europe it is a common sight that experts, professors, doctors and scholars take part-time jobs as tour guides. Such a usual practice not only upgrades a nation's culture propagation, but also improves the publicity's effect. A large majority of countries in the world attach great importance to the social effects of the culture spreading by tourism practitioners, which is highly valued as an important strategy to improve the overall strength of a country.

\subsection{Characteristics}

Most Occidental travelers may have only one opportunity during his life to come to China due to far distance and large expenses. He or she needs to acquire nice and direct impressions on China and the people there as much s possible just in a few days during their life time. So the quality of the direct impression is unidirectional, which means that the impression can be merely positive, but not negative. Further, Chinese tour guides should put the time constraint into account and help their guests take a most possible successful tour so that they can go back to their home country with beautiful impressions on Chinese culture. This is the first characteristic of tourism cross-cultural propagation.

Tourism cross-cultural propagation is different from the propagation of other types of cultural knowledge, such as the education programs for the foreign students who come to China for further study. This is because, for most people living in modern society, traveling is a means of self-relaxation which removes the mental and physical burdens caused by the fast life pace, hence, it can be regarded as a consumption which combines vocation, leisure and entertainment. To meet such consumer's needs, cross-cultural propagation of tourism should be conducted in an atmosphere of lightness and pleasantness. Chinese culture can be explained to foreigners in simple and tasteful terms and cultural propagation be merged into the activities of leisure and entertainment. This is the second characteristic of cross-cultural propagation of tourism.

Tourism industry creates good opportunities for friendly communication and mutual understanding between peoples of different regions and countries. Cross-cultural propagation of tourism has constructed a bridge of communication and mutual understanding between different cultural communities. It improves opportunities for peoples from different cultural backgrounds to perfect their cultures with the civilization cream of other nations. This is because culture can be communicated and understood by peoples of different nations in nature. In this sense peoples with similar cultural interests can become intimate friends. When cultural conflicts occur a tour guide should respect the cultural values and customs of the guests and reduce negative effects of a cultural collision. Patiently and gradually the tour guide can exchange feelings and ideas with the visitors and stimulate them to learn about and understand Chinese people's life style, pattern of logical thinking, norms of behavior, morality, sentiment, ascetic interest, life philosophy as well as customs and conventions. As a result, friendship will be enhanced and deepened. This is the third characteristic of tourism cross-cultural propagation.

\section{Requirements for Foreign Language-speaking Tour Guides}

Mainly, tourism cross-cultural propagation is represented in guest-receiving process and the process has to be completed by foreign language-speaking tour guides. Without highly professional quality, the guides cannot achieve any success in tourism cross-cultural propagation. Quality is a stable competence acquired by assimilating and sublimating knowledge. And skills are learned and accumulated through long term practice. To be successful in cross-cultural propagation, the tour guide is required to develop the following qualities:

\subsection{Rich cultural knowledge about Chinese nation and the people}

Generally, travelers choose natural landscapes and famous historical sites as the objects to visit. Understood on the surface, a tour guide's work is only navigating the visitors form one scenic spot to another. From this assumption, it is concluded that tour-guiding is merely leading the way for visitors. This is only a shallow misunderstanding. The assumption has depreciated the profound cultural connotation of the scenery and sightseeing. Besides, it ignores the traveler's needs to participate in various activities and underrates the roles that a tour guide performs in the cultural propagation during a tour. To be competent for the cultural propagation, a foreign language-speaking tour guide must equip himself with a rationally structured knowledge preserve.

First, he needs to possess extensive knowledge about Chinese traditional culture. Often, tourists of different age, career and education background require the guide offer large spans of cultural knowledge, which ranges from magnificent wars and famous historical events to mental and physical cultivation, musical instrument playing, flower-growing and fish, insets and birds raising, etc. Academically, the knowledge involves not only historical relics, archaeology, literature, art, religion, medicine, architecture, park design and building, gardening, folk customs and conventions, but dress and 
personal adornment, weaponry and entertainments as well. When presented vertically, Chinese culture carries the features of the historic inheritance, but horizontally, it includes not only the culture of the Han ethnic group but also that of other nationalities. It is a combination of native and external cultural works of art. As for appreciative taste, a tour guide's speech should be both elegant and popular. When preparing a speech a tour guide may need only a countable amount of knowledge, but he must possess a large store of diversified knowledge. Such a rich storage means a wide spectrum of material selection to him.

To give wonderful explanation about scenic spots and landscapes, the tour guide needs to absorb fine and important material from historical data, anecdotes, legends, events and well-known figures, etc. Only when well grounded and highly adaptable to various situations can he make his speech fascinating to the audience.

In addition, he should explore the knowledge about a particular subject, for example, when the present architectural style and feature of a sightseeing building are being studied, the previous and post features and styles must be put into account so that the building evolution process can be studied and the comprehensive architectural culture of China be grasped as a whole. Meanwhile, a comparative study needs to be made between China's ancient architectural styles and features and those of ancient European building, which will be helpful for the visitors to learn about the difference of the two and deeply realize the cultural connotation of the visited scenic spot.

Furthermore, the guide should make profound studies on the Chinese culture in extensive horizons, for instance, Confucianism, Buddhism and Taoism respectively exert specific influences on varieties of cultural arts of ancient China. A thorough and comprehensive knowledge of the three fields will enable the tour guide to master the traditional culture in general. Such mastery serves as a solid foundation for the guide to explain briefly and clearly the particularities of a certain area of the traditional Chinese culture. Then, his cross-cultural propagation will be upgraded to a higher level.

\subsection{Rich cultural knowledge about the guest country and the people}

A qualified foreign language-speaking tour guide should not only possess plenty of the cultural knowledge of his native land but also that of the guest country. He must be familiar well enough with the guest country's fresh and modern culture in dynamic condition as well as its historic and traditional culture in static condition and acquaint himself with the highly tasted main stream culture and the regional and popular minor stream culture as well. That is the only solution to finding out the commonality and compatibility between the two.

The most important ability to become acquainted with two particular cultures is being good at making comparisons between them and obtaining referential findings. For instance, in Europe the gardening art is regarded as an art of planting, which is to symmitrize flower forums, lawns and plants in palaces and castles. The effect is to build a comfortable ecologic environment for people's social contact and art appreciation. On the contrary, the principle of the classical Chinese garden art is to re-create nature. It is to add poetic quality to natural sceneries in accordance with man's ideal. The aim is to create an ideal ecological condition of tranquility and coziness. The designing philosophy is different, one gives more highlights to vegetation planting art, and the other emphasizes scenery recreation. But both aim at creating an ecological environment of social life. This is the common features of the two types of gardens. Between them, there is no difference of being superior or minor, but only the compatibility to each other. If a foreign language-speaking tour guide take this feature as the initial tone for his speech, it will be easier for him explain clearly and precisely the unique style and art charm of the classical Chinese garden design and decoration to the visitors and reveal the cultural connotation and aesthetic value to them.

With extensive and profound cultural knowledge, a tour guide is able to capture the thread of his communication with the visitors. For example, German attaches great importance to logic reasoning and philosophic presentation. They are keen on exploring the essence of anything in the discussion. When explaining "Buddhism suffering" of "The Four Noble Truths", the guide is frequently interrupted by such instant questions as what the suffering really is in Buddhism. A resourceful guide would make comparisons between the Buddhism suffering with the saying "the nature of man's will is suffering.", the perspective of Arthur Schopenhauer, a German philosopher in $19^{\text {th }}$ century. Summarizing the comparison, he concluded that both pessimistic views are essentially different from the initiative spirit of modern people. Such an explanation gave the audience an unexpected pleasure. To the visitors, this pleasant surprise means not only a reward to the guide for his wittiness, but also an excitement of suddenly finding out the passage of communication between Chinese and European cultures by themselves.

In making cross-cultural propagation, a tour guide should be good at finding best turning point of topic and in which area the guests are interested. For example, most of Austrian like to enjoy music and take John Strauss and Mozart as their national pride. The majority of them know well about jasmine, a piece of Chinese folk music work. But quite a few of them have a bit of knowledge about A Moonlit Night On The Spring River, The Moon Over a Fountain and the Butterfly Lover and other famous Chinese music works. If the guide can catch the opportunity and make appropriate introduction immediately to arouse the interest of the visitors, the latter will be stimulated and become fascinated in the music, just like making a discovery of a new continent. This is the musical commonality, in essence, a kind of cultural compatibility which has to be realized by the guide's skillfully applying his tour guiding art. 


\subsection{Proficiency in English or other foreign languages}

A foreign language works as a linguistic equipment of cultural propagation. For a tour guide the foreign language he speaks is just the native tongue that his receiving object uses. People who speaks a certain language belongs to a particular (or just a few) race, or a community whose physical features are somewhat different from those of another. This is one of the features that a cultural community bears. With these features people who speak the same language feels affinities to each other and shares psychological intimacies. Why are travelers willing to follow the guide's advice abroad or in a remote area? They speak the same language and feel intimate to each other. This explains why contacts and communication occur between the guide and visitors promptly on arrival of the destination.

To understand the unfamiliar environment and new cultural phenomena, visitors need the guide's assistance to deepen the contacts and communication. Also, they rely on him to clear up doubts. Only when the guide's language proficiency and competence of cultural communication are adequate enough to meet the traveler's need to learn about and understand the fresh world and have been recognized by the travelers can the contacts and communication be thorough and comprehensive.

The tour guide has to breakthrough the psychological constraints from different cultures. In delivering a speech, his presentation in a foreign language is often affected by his native culture, or vice versa, his interpretation on Chinese culture is occasionally blocked by the foreign culture. If his thinking pattern in mother tongue affects the expression in a foreign language, the normal communication process will be disturbed even broken. Conversely, when the cultural connotation interpretation in the native tongue is confined by the mode of thinking in the foreign language, the presentation about the native culture will lose fidelity. This is the tough nut in cross-cultural communication. Such a challenge indicates the power to overcome cultural barriers is of great importance to a foreign language-speaking tour guide. He must take a perfect command of the foreign language by comparative studies on cross-cultural psychology, which will enable the foreign language competence equally matches the native speakers. This is an ideal state of language proficiency, which is magnificently useful in smooth cross- cultural communication.

\subsection{Flexible and constantly improved art of guiding}

One of the most important art of guiding is to attract the visitors' attention by offering them the most suitable and timely explanation about what they are thirsty to know. The key is to make full use of the guide's individuality to comprehend visitors' psychological needs. As a mental activity, attention exerts external influences on the traveler. Attention stimulating is a basic skill of guiding service. Only through the emotional and ideological system of the audience can the external influence produce psychological effect. Therefore, the technique to arouse the visitor's attention must suit the visitor's "established emotional and ideological system". In this way cultural propagation is making impacts on the visitor's mind and the visitors are deeply impressed by the splendid Chinese culture.

Mostly, the guide depends on his speech to attract and keep the audience's attention, but the speech must be adaptable to constantly changing situation. Often, the negligence of the visitor's needs and a fixed package of speeches will make visitors feel dull and boring and cause the guide himself become insensitive to different needs of the visitors. So the value of a speech lies in creation and original ideas. The present theme of a speech needs to be deeply excavated, which is the source of vigor and charm that helps the guide keep the audience keen on a particular topic. Usually, the creation is promptly completed on the spot, a situation the guide can draw on to demonstrate his talents to the guests. With repeated practices he gradually endows himself with a cognitive power to detect and catch the visitor's mentality at the right moment so as to arouse a shared emotional resonance between the speaker and the listeners and attract their attention. Gradually, this personal experience will become the power to offer excellent speeches and commentaries.

Stylistic uniqueness is an important factor of attention attraction which requires the tour guide possess an excellent discerning power. He should be adept in organizing fragmentary source material into consistent literary pieces so that his speeches will sound brief, precise, lucid, lively and coherent to the listeners and be adaptable to specific time, place, audience and situation. Whether the presentation is natural or passionate, plain or poetic, its unique style, distinct theme and rich and colorful content should be able to enlighten the audience's ponderation and imagination and bring them ascetic association. Without the visitor's enthusiasm of beauty appreciation, tourism cross-cultural propagation cannot produce desirable effect.

\subsection{Patriotic consciousness and self respect}

In conducting the cross-cultural propagation, a foreign language-speaking tour guide is essentially required to be patriotic and passionate with the culture of his home nation. Primarily, the guide's patriotic feeling is represented in his love and dedication to the present job. This spirit encourages him make pains-taking efforts to overcome various difficulties in his work. With such a spirit, he will constantly improve his serving skills and contribute greatly to spreading the Chinese culture in most parts of the world.

The patriotic awareness is also represented in his mental outlook and cultural cultivation. Both Oriental and Occidental peoples take the cultural cultivation level as the dimension to measure a man's personality. What personality does a tour 
guide demonstrates in his work is normally regarded, by foreign guests, as the embodiment of a country's national image and its cultural spirit. So he is often reputed as "the mirror of the motherland".

Actually, the tour guide is propagating the Chinese culture in a linguistic context of interacting with the visitors on political, economic and cultural affairs and he is talking with the world. While introducing the brilliant Chinese culture to foreign friends, the tour guide is obligated to keep the national secret, such as scientific, technological and business information from being released and protect rare animal, plants and cultural relics from being smuggled abroad.

\section{The Basic Significance of Tourism Cross-cultural Propagation}

Briefing the above, some conclusive perspectives can be drawn out:

3.1 Further exploration on the theory and practice of cross cultural propagation is helpful for training and producing great numbers of foreign language-speaking tour guides with excellent professional qualities and cultural taste. The work in this regard is of great realistic significance to tourist economic growth and the industrial prosperity.

3.2 It will facilitate establishing an effective mechanism to learn, absorb and draw on all of the cultural achievements created by the entire human being, especially those of modern society. Tourism industry, as a bridge of cultural communication, serves well to strengthen the country's contact with other excellent cultures. It will contribute to promoting the splendid Chinese culture in most parts of the world and enables the culture become a common cultural wealth of the whole mankind.

3.3 The exploration will improve the friendship and mutual understanding between different nationalities and promote the peaceful development of most countries of the earth.

\section{References}

Liu, Yin. (2008). The Influences of Foreign Language-speaking Tour Guides on Trans-cultural Propagation, Science. Technology and Education, 7.

Wang, Weihua. (2006). Analysis and Consideration on Tourism Cross-cultural Propagation. Journal of Post Graduates of Huazhong Normal University, 3.

Wu, Xiaoyi \& Lin, Derong. (2008). A Summary of the Research Achievements on Tourists' Consumption Behaviour. Tourism Science, 3. 